\title{
Mapping Sentiment: National Anthems and Interstate War
}

\author{
MARINKO BOBIĆ* \\ Leiden University, the Netherlands \\ JAROSLAW KANTOROWICZ** \\ Leiden University, the Netherlands
}

National anthems are written at a particular time for a particular purpose. Of course, there are also instances where the text evolves and is being adjusted to the new context and circumstances. According to rhetorician Xing Lu, political songs in general "convey powerful rhetorical messages, address rhetorical exigencies, express ideological agenda, arouse emotions, and stimulate actions". ${ }^{1}$ Cerulo claimed that national anthems, together with flags, are the strongest, clearest statement of national identity, serving to "create bonds, motivate patriotic action, honor the efforts of citizens, and legitimate formal authority". ${ }^{2}$ similar claim is made by Spenser and Wollman. ${ }^{3}$

Based on the aforementioned claims that national anthems reflect past efforts and potentially future agendas, this preliminary research investigates the correlation between the number of wars and the sentiment of national anthems. The focus of this study is on the interstate conflicts knowing that anthems frame national identities as cohesive.

Using English translations of nearly all the contemporary anthems, we assessed the sentiment strength of each state's anthem, and its relationship with the number of its Militarized Interstate Disputes. ${ }^{4}$ We discovered tentative findings that the total number of interstate conflicts of contemporary states is strongly, negatively, correlated with their anthem's positive sentiment (Spearman's rho $=-0.1573$ ). In other words, the higher the number of interstate conflicts a state experienced before and after its anthem's lyrics were written, the more likely it is that the anthem will have a higher negative sentiment ratio, and a lower positive sentiment ratio. This relation can also be seen in Figure 1.

1 Xing Lu 2004, 118.

2 Cerulo 1993, 244.

3 Spenser and Wollman 2005.

4 Palmer, D’Orazio, Kenwick, and Lane 2015.

*m.bobic@fgga.leidenuniv.nl

**j.j.kantorowicz@fgga.leidenuniv.nl 


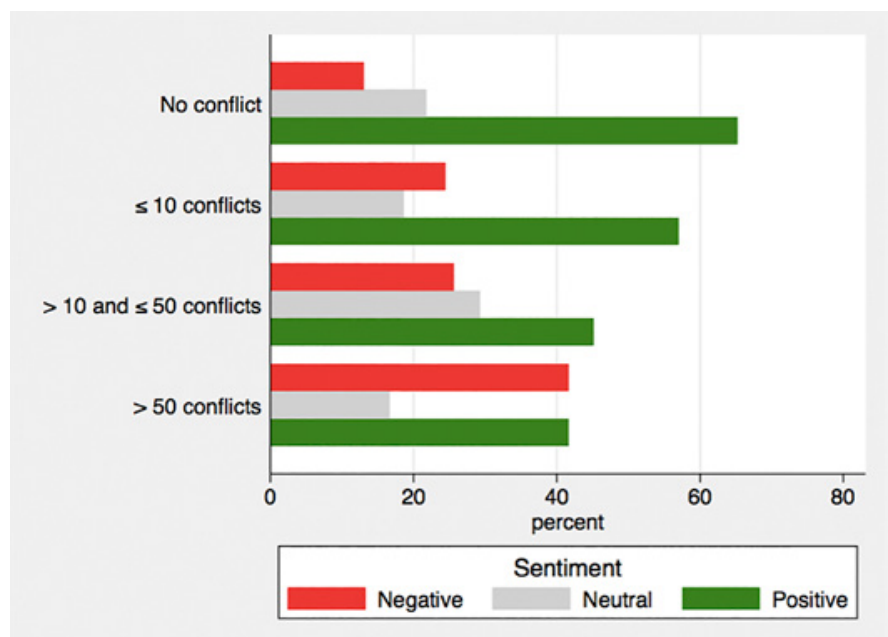

Figure 1: A chart illustrating the relationship between the number of conflicts (y-axis) and the percentage of cases containing each of the following ratios: negative, neutral, and positive ( $x$-axis)

This can be interpreted in several ways. Negative sentiment of a national anthem may reflect a nation's negative experience of being involved in costly wars of the past, such as fighting for independence or even attempts to revise the international system, conquer territories, or undermine rivals. Such conflicts may have been defensive or offensive. What about states whose national anthems were adopted at the beginning of their independence, thus preceding interstate conflicts? In that case, the negative sentiment may also reflect a nation's overall bellicosity, generally negative view towards the international society or other states, meaning that such negative view may contribute to increased security dilemmas, tensions and inevitably armed conflicts. Difficulty in assessing anthems written a priori compared to those written a posteriori to the conflict is that texts are often adapted, changed, as are the state names, borders and ethnic compositions. Therefore, the results here should be understood as tentative.

The methodology is based on SentiStrength, an automatic sentiment analysis software which places each anthems' text on a score from -4 (extremely negative) to 4 (extremely positive). Sources of the lyrics of anthems are listed below. The correlation and the mapping of the sentiment strength was performed in STATA (spmapuser written command). Spain, Bosnia and Herzegovina, San Marino, and Kosovo were included with their unofficial lyrics. Some anthems have official English translations while others were translated via google translate. ${ }^{5}$

5 On the efficiency of Google Translate, see de Vries, Schoonvelde and Schumacher 2018. 
Given the exploratory research of this work, further analysis needs to be done to strengthen the relationship between conflicts and national anthems. More specifically, one way could be to enquire whether the relationship holds if we also account for historical cases. Further research, among other, should differentiate anthems written before and after the wars, taking into account the adaptations of lyrics and including the onset of civil wars in the analysis. Another option could be to differentiate offensive and defensive wars. It might also be possible to group anthems according to themes.

\section{References}

Cerulo, K. A. 1993. "Symbols and the World System: National Anthems and Flags.”Sociological Forum8(2): 243-271.

deVries, E., M. Schoonvelde, and G. Schumacher. 29 August 2018. No Longer Lost in Translation: Evidence that Google Translate Works for Comparative Bag-of-Words Text Applications.

Lu, X. 2004. Rhetoric of the Chinese Cultural Revolution. Columbia, S.C.: University of South Carolina Press.

Palmer, G., V. D’Orazio, M. Kenwick, and M. Lane. 2015. The MID4 Data Set:

Procedures, Coding Rules, and Description. Conflict Management and Peace Science, forthcoming.

Spencer, P., and H. Wollman. 2005. Nations and Nationalism: A Reader. New

Brunswick, NJ: Rutgers University Press.

\section{Sources of anthems}

www.lyricsondemand.com

www.wikipedia.org

www.nationalanthems.info 


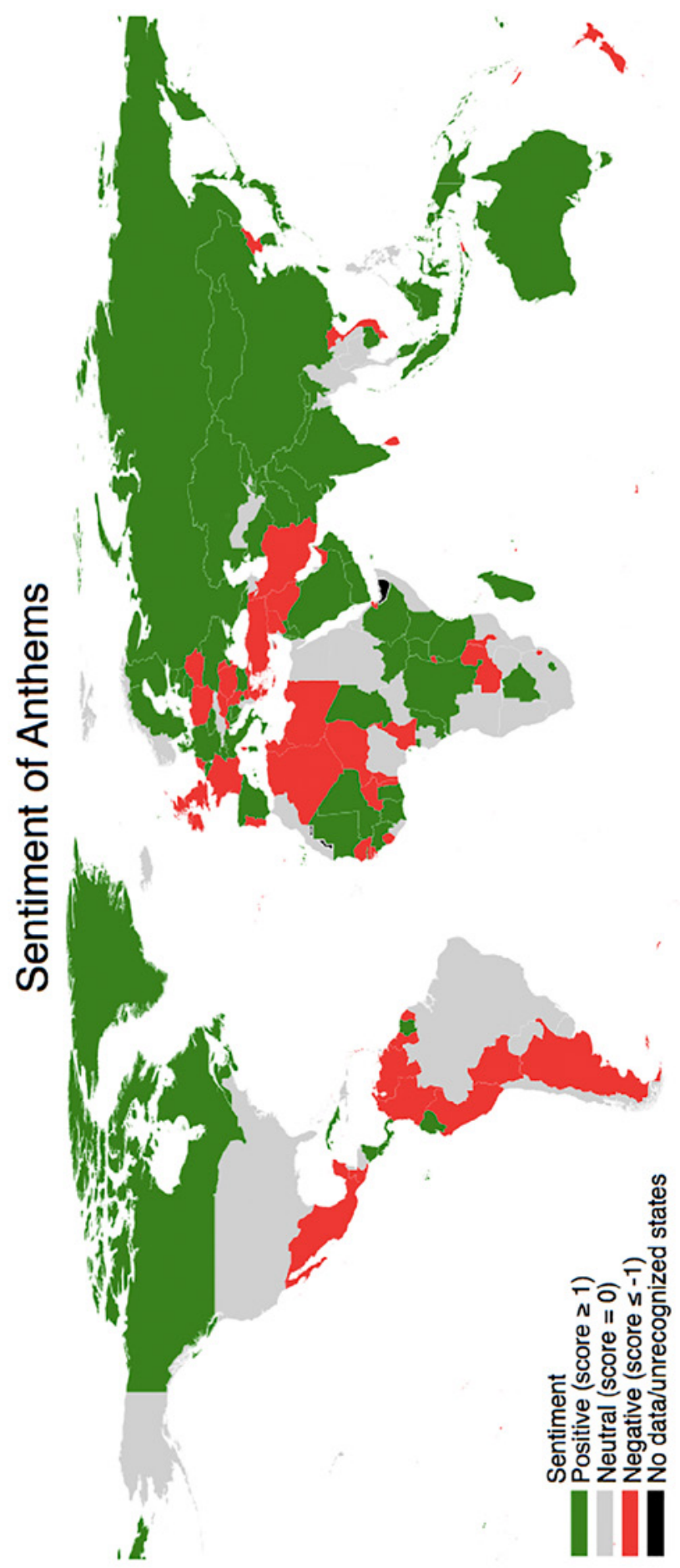

